
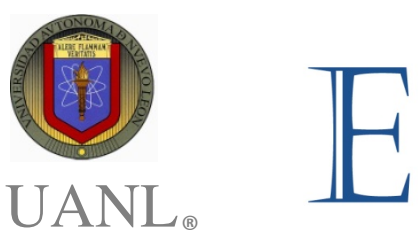

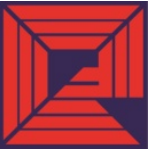

Facultad de Economía

\title{
La insostenibilidad del desarrollo en las entidades federativas de México
}

\section{The Unsustainability of the Development in Mexican States}

\author{
Lilian Albornoz Mendoza* ${ }^{*}$ \\ Rafael Ortiz Pech \\ Rodolfo Canto Sáenz*
}

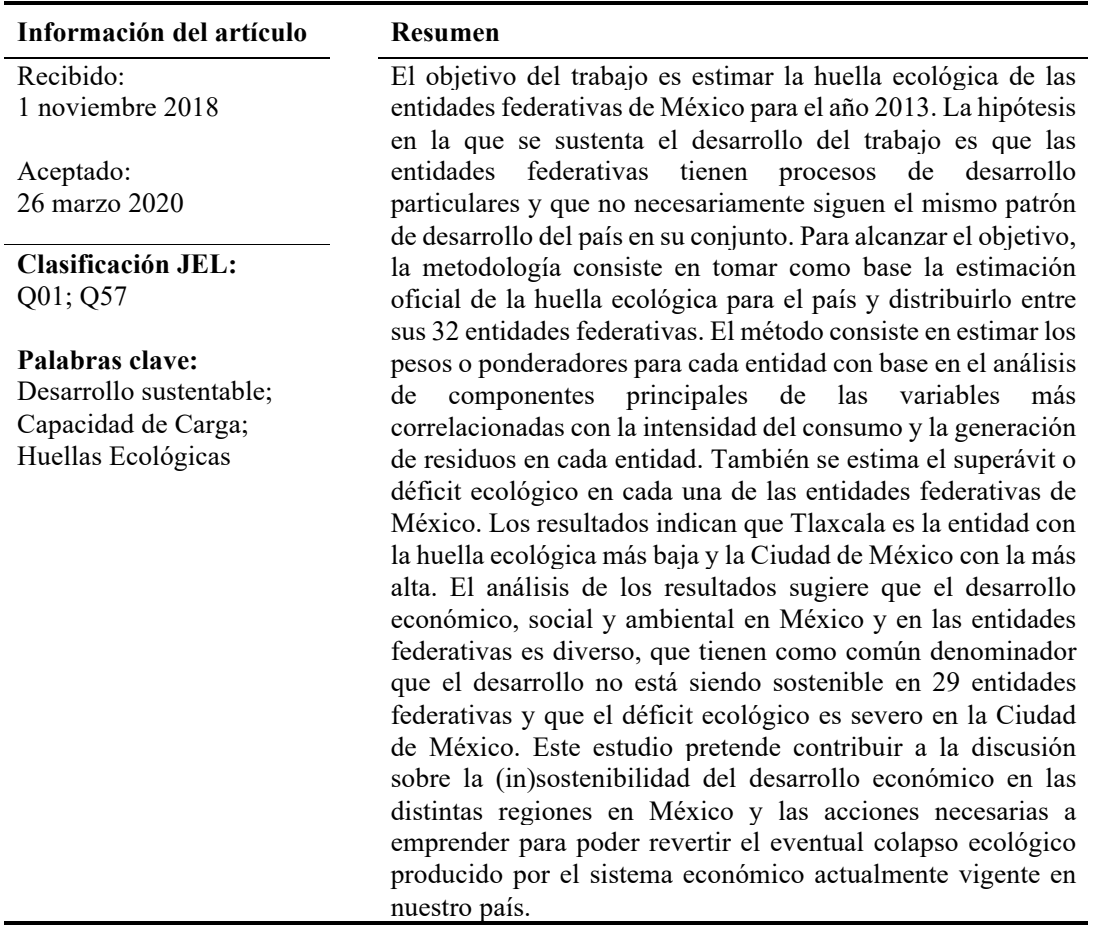

*Facultad de Economía, Universidad Autónoma de Yucatán, México;

$\dagger$ email: lilian.albornoz@correo.uady.mx

ISSN Electrónico: 2448-8402 | ISSN Impreso: 1870-221X | (C2020 Los autores @) (c) Citar así: Lilian Albornoz Mendoza, Rafael Ortiz Pech y Rodolfo Canto Sáenz (2020). La insostenibilidad en las entidades federativas de México. Ensayos Revista de Economía, 39(1), 59-86, http://dx.doi.org/10.29105/ensayos39.1-3a 


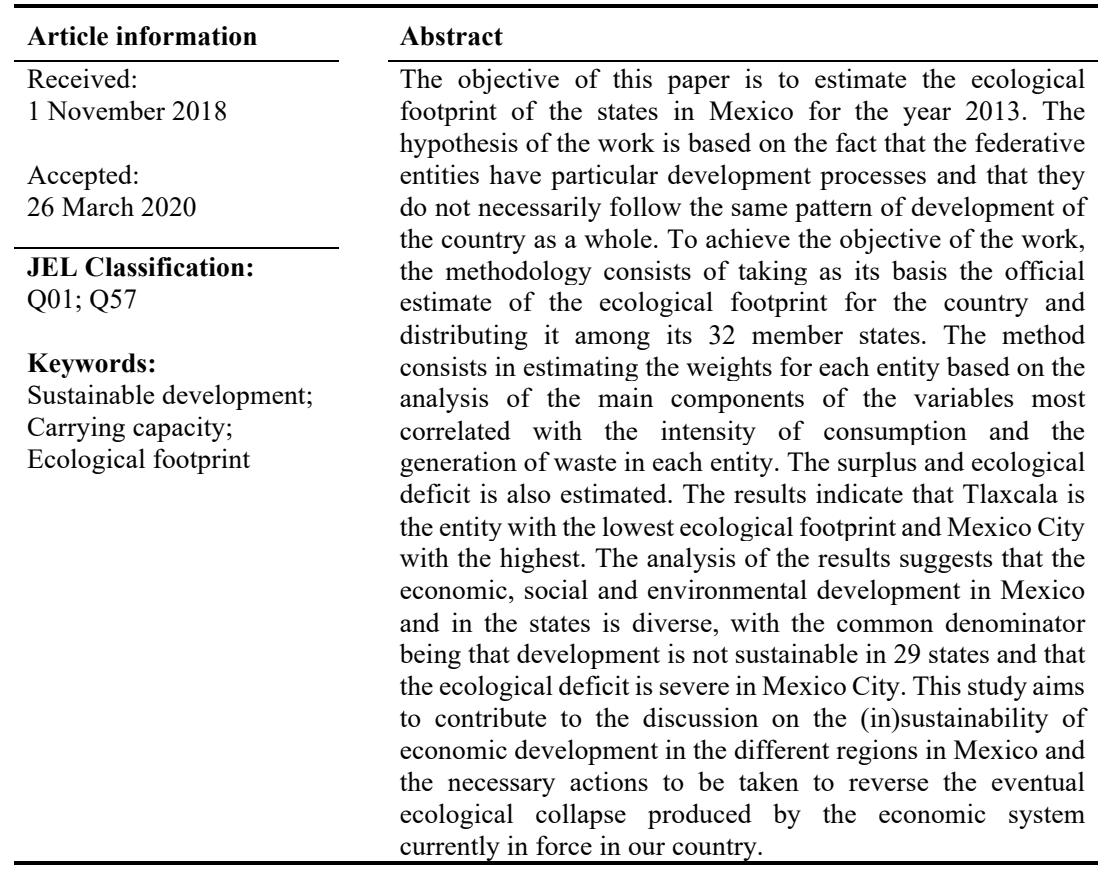

\section{Introducción}

En el año 2015, la comunidad internacional desarrolló una nueva agenda de desarrollo con el fin de renovar el compromiso establecido en los Objetivos de Desarrollo del Milenio (ODM). La agenda tiene como fin orientar la política de desarrollo sostenible de los países de la comunidad internacional hacia un futuro sin hambre, con suficiente comida para todos, así como dotar a la población con trabajos decentes, entre otros fines. Es un conjunto de 17 acciones u Objetivos de Desarrollo Sostenible (ODS) que tiene como fin organizar la producción, la estructura del consumo y la acumulación de la riqueza de una economía local de acuerdo con los principios de la sostenibilidad de los ecosistemas locales y globales en la satisfacción de las necesidades materiales de la población local.

Sin embargo, las acciones a emprender como parte de dicha agenda deben considerar las condiciones particulares de las regiones donde se implementarán para que los resultados estén en línea con las metas esperadas. Las estructuras económicas, sociales y políticas que configuran un territorio particular determinan el proceso de desarrollo de dicho territorio y condicionan los resultados de un conjunto de acciones de política pública. Se entiende por estructura económica a la estructura de organización de la producción del conjunto de industrias locales, la estructura del consumo intermedio 
interindustrial y consumo final de los hogares/gobierno/resto del mundo y la acumulación de la riqueza por los agentes económicos domésticos. La estructura social en cuanto al flujo de las remuneraciones a los factores de producción y la redistribución del ingreso a los hogares. Y la estructura política en cuanto a las decisiones que se toman, los programas de política que configuran los incentivos y las acciones de los agentes en la economía local.

Es necesario sentar las bases para la reconfiguración de las estructuras de las economías locales en concordancia con los principios de las sostenibilidad social, económica y ambiental con el fin de alcanzar los resultados esperados en la agenda de desarrollo sostenible. Una herramienta que sirve de base para la planeación del desarrollo sostenible es la huella ecológica, como medida de la capacidad de los ecosistemas locales en proveer los satisfactores que demanda la población de un territorio en particular. Aun cuando la huella ecológica solo mide un aspecto de la sostenibilidad a decir, la biocapacidad de los ecosistemas y sus límites, es una herramienta que sintetiza información útil para la toma de decisiones.

La huella ecológica se basa en el principio de la sustentabilidad fuerte como criterio para administrar y organizar una economía en particular. La sustentabilidad fuerte requiere del mantenimiento continuo del acervo de capital natural como fuente de insumos o materias primas y de sumidero natural para la absorción de los desechos y, por lo tanto, se basa en la tesis de que la capacidad de regeneración de los ecosistemas es el factor limitante para la escala de la actividad humana. Hasta el momento, las estimaciones de la huella ecológica registran el consumo de recursos y energía de economías nacionales, pero recientemente se están haciendo esfuerzos para estimar las huellas de economías a una escala menor, como es el caso de entidades federativas, regiones o localidades en particular.

La sostenibilidad del desarrollo es más relevante a nivel local dado que es el espacio donde se pueden establecer políticas y programas de manejo más adecuados a los fines establecidos en dichas políticas. El contexto local es de suma importancia en los planes de manejo ambientales dado que el uso de recursos naturales está vinculado al sistema económico de un territorio particular. El espacio de un territorio particular es el marco más adecuado para la planeación del uso de recursos, para organizar la estructura económica con base en la dotación de los recursos disponibles y administrarlos de acuerdo con las directrices de planes y programas de manejo sustentables locales. La huella ecológica es el instrumento por excelencia que orienta la toma de decisiones en el marco de la planeación del desarrollo sostenible en un territorio en particular.

El presente trabajo tiene como fin generar información para la toma de decisiones de política pública. Con base en dicha información se pretende 
demostrar la hipótesis de este trabajo de que el desarrollo económico, social y ambiental en las entidades federativas es diverso y que tienen como común denominador que el desarrollo no está siendo sostenible, de acuerdo con el análisis de huella ecológica que se presenta en este trabajo. La hipótesis del trabajo se contrasta con base en una metodología de análisis multivariado conocida como análisis de componentes principales, la cual permite la estimación de las huellas ecológicas y el déficit/superávit ecológico de cada una de las 32 entidades federativas de México.

Este estudio pretende contribuir a la literatura especializada sobre huellas ecológicas en México, en especial a la discusión sobre la (in)sostenibilidad del desarrollo económico en las distintas regiones en México y las acciones necesarias a emprender para poder revertir el eventual colapso ecológico producido por el sistema económico actualmente vigente en nuestro país. Con base en los resultados, se encuentra que Tlaxcala es la entidad federativa con la huella ecológica más baja (1.4 gha/pc) y la ciudad de México con la huella ecológica más alta $(4.7 \mathrm{gha} / \mathrm{pc})$. Por otra parte, 29 entidades federativas presentan déficit ecológico, siendo la Ciudad de México la entidad con el déficit más alto. Destacan los casos de Sinaloa, Durango y Sonora con oferta neta positiva de biocapacidad o superávit ecológico.

El artículo se estructura de la siguiente forma: después de la introducción, en el primer apartado se presenta el marco teórico-conceptual que sustenta el análisis realizado en el tema de desarrollo sustentable; en el segundo apartado se desarrolla la metodología para la estimación de las huellas ecológicas, capacidad de carga local y superávit/déficit ecológico; en los apartados tres y cuatro, se presentan los resultados del estudio; y, por último, las conclusiones a manera de resumen final.

\section{Marco Teórico}

\subsection{Orígenes de la sustentabilidad}

El término sostenibilidad ambiental es de reciente uso en el siglo $\mathrm{XX}$, aunque sus raíces se desarrollaron en el siglo XVIII con las aportaciones de la escuela de pensamiento de los fisiócratas y los economistas clásicos. Los fisiócratas fueron los primeros en abordar las preocupaciones por los recursos naturales, en especial la tierra, porque según ellos la actividad económica real consistía en trabajar la tierra y todas las demás actividades no generaban riqueza sino dependían de aquella creada por la madre tierra. La explotación de la tierra y sus recursos naturales según esta escuela debía llevarse a cabo sin afectar el stock de los recursos y los esfuerzos se deberían orientar al incremento de las riquezas renovables. Por su parte, economistas clásicos (Robert Malthus, David Ricardo, John Stuart Mill) abordaron las limitaciones de la capacidad de 
la tierra para satisfacer las crecientes necesidades de alimentos de la población y los incrementos en los precios de los alimentos. Su planteamiento es un antecedente del reconocimiento de la imposibilidad del crecimiento económico creciente y la armonía entre el bienestar material de la población y los recursos naturales del ecosistema (Rodríguez, 2004).

En el siglo XIX y XX destacan las aportaciones de renombrados científicos que contribuyeron a sentar las bases del desarrollo posterior en el marco del desarrollo sustentable. Por un lado, las preocupaciones de Stanley Jevons, economistas neoclásico, al destacar la alta dependencia de la economía británica en la explotación de un recurso natural no renovable (carbón mineral) con fines energéticos, preocupaciones se han trasladado al ámbito de la economía mundial debido a la alta dependencia energética de las naciones en el uso y aprovechamiento no sustentable de las fuentes de recursos fósiles no renovables como el petróleo, carbón y el gas natural que además contribuyen a la emisión acelerada de partículas que elevan la temperatura y conducen al calentamiento de la superficie de la Tierra. También destacan las siguientes contribuciones de: Alfred Pigou destacó la existencia de externalidades que conducen a fallas en los mercados dado que los precios del mercado no internalizaban el daño que hacen a la naturaleza, Harold Hotelling quien planteó que el manejo de los recursos naturales debe realizarse en función de la tasa de interés del mercado aunque esta regla no garantice la conservación de los recursos naturales y muy probablemente induzca a la explotación no sustentable de los mismos, Garret Hardin sobre la administración de recursos de acceso abierto, Nicholas Georgescu-Roegen con la Ley de entropía y el proceso económico y padre de la economía ecológica y Herman Daly sobre el estado estacionario de una economía, entre otros (Albornoz, 2015).

A partir de las aportaciones anteriores, $\mathrm{y}$ en respuesta a las preocupaciones por los problemas ambientales, en el año de 1983 la Organización de las Naciones Unidas creó la Comisión Mundial de Medio ambiente y Desarrollo a la cual encomendaría la elaboración de un informe denominado Nuestro Futuro Común también conocido como Informe Brundtland, el cual fue presentado en el año 1987 (ONU, 1987). En el informe se oficializó por primera vez el término desarrollo sustentable que versa así: "en esencia, el desarrollo sostenible se puede definir como un proceso de cambio en el cual la explotación de recursos, la dirección de las inversiones, la orientación del desarrollo tecnológico y el cambio institucional todos en armonía y orientados a mejorar el potencial presente y futuro para satisfacer las necesidades humanas y sus aspiraciones " (WCED, 1987, pág. 43).

A partir de la definición oficial, se han desprendido un sinnúmero de aportaciones de distintas corrientes del pensamiento que han enfocado el concepto desde diferentes perspectivas, dentro de estas se pueden distinguir a 
tres de las más importantes: el enfoque de los tres pilares, el del ecosistema y el del capital. El enfoque del capital se basa en la idea del mantenimiento de un flujo de ingresos a partir de una administración y gestión eficiente del patrimonio o riqueza (natural y no natural) del país. El enfoque del capital surgió en el seno de la ciencia económica, sin embargo, ha adoptado elementos de otras disciplinas (ecología, geografía, ciencias de la tierra, termodinámica, dinámica de sistemas, entre otros). Para la corriente que ha adoptado este enfoque el desarrollo sustentable se puede definir como aquel estado que garantiza un nivel mínimo de bienestar con base en la gestión y mantenimiento de un stock de riqueza que genera un flujo constante o no decreciente de ingresos per cápita. La riqueza de un país está determinada por los recursos y servicios que suministra el ecosistema (capital natural), el capital físico que permite la producción de otros bienes (maquinaria, edificios, infraestructura en general), las habilidades-destrezas de los trabajadores en la realización de las actividades económicas (capital humano) y la capacidad para organizarse y tomar decisiones colectivas (capital social). El capital engloba los cuatro tipos de capital natural, físico, humano y social que deberán ser administrados y gestionados de tal forma que el flujo de ingresos que genere sea lo suficientemente elevado sin provocar menoscabo en las funciones y en los acervos del mismo (United Nations, 2003).

Entre los científicos de esta corriente, hay consenso en el sentido de que se debe mantener un stock mínimo de capital agregado, sin embargo, el consenso se pierde al determinar el tipo específico de capital que se debe preservar. En este debate, se distinguen dos extremos opuestos: los que opinan que el capital natural se puede agotar y degradar ya que puede ser sustituido perfectamente por capital físico producido por el hombre. En esta situación, el capital físico es un sustituto perfecto del capital natural, las máquinas o desarrollos tecnológicos pueden remplazar el recurso natural como los fertilizantes sintéticos han sustituido la falta de fertilizantes naturales por erosión de suelos. Por otro lado, están los que opinan que el capital natural es complemento del capital físico y, por lo tanto, el primero debe ser preservado. Los árboles de un bosque y las sierras eléctricas son complementos, se necesitan los dos tipos de capital para llevar a cabo el corte de las cortezas de los árboles, sin los árboles las sierras no tienen utilidad y valor. Ambas posturas han dado lugar a dos tipos de acepciones del concepto de sustentabilidad: la débil que considera sustitutivos perfectos los distintos tipos de capital y que está representada por la corriente de pensamiento de la economía ambiental y la fuerte con unidades de capital que se complementan representada por la corriente de pensamiento de la economía ecológica (United Nations, 2003). 


\subsection{Huella ecológica y la sustentabilidad fuerte}

La huella ecológica es un marco contable que sirve para cuantificar los servicios biofísicos ${ }^{1}$ de la naturaleza que requiere una economía dada (Wackernagel, 1994). Se calcula estimando el área de tierra necesaria para sostener el nivel de consumo actual de la población en una economía dada, usando la tecnología prevaleciente. Comprende todos los recursos y servicios ecológicos locales y globales que son apropiados por una economía para proveer materias primas, energía y para asimilar los desechos de la producción y el consumo, expresados en unidades de tierra (hectáreas).

La huella ecológica es un término para denominar a una herramienta de gestión y planeación de la sustentabilidad. Es una herramienta que mide los impactos biofísicos de la actividad de producción y consumo, en un indicador simple y que se basa en el principio de la sustentabilidad fuerte. En este sentido, la huella ecológica es una medida biofísica del capital natural (Wackernagel et al., 1999) y para el cual se utiliza como aproximación una unidad de medida homogénea operativa denominada superficie de tierra bioproductiva expresada en hectáreas globales (de tierra y mar).

La huella ecológica representa los requerimientos de capital natural ${ }^{2}$ de una economía en términos de su correspondiente área bioproductiva. La superficie bioproductiva tiene distintas acepciones, pero la que sirve de base al concepto es la cantidad de biomasa (producción primaria neta) que puede generar un área determinada (una hectárea) teniendo como referencia de cálculo la productividad global media del ecosistema. La huella ecológica enfoca su análisis desde la perspectiva de consumo de la población (perspectiva no territorial a diferencia del enfoque de la producción, esto es, perspectiva territorial) y todos los insumos, recursos y servicios biofísicos necesarios de manera directa e indirecta para satisfacerlo, expresado en hectáreas globales de tierra bioproductiva (Cano, 2004; Wackernagel et al., 1999; Borucke et al., 2013; Albornoz, 2015). Es decir, la demanda de recursos y servicios biofísicos

\footnotetext{
${ }^{1}$ Son cinco los servicios biofísicos que presta la naturaleza: proveedor de materias primas, proveedor de energía para la producción de bienes y servicios, capacidad de asimilación de desechos de las actividades humanas, servicios de soporte de la vida (capa de ozono, regulación del clima, biodiversidad) y como paisaje para la recreación (United Nations, 2003, pág. 1).

2 El capital natural se puede clasificar en tres categorías: recursos naturales, tierra y ecosistemas. El System of Environmental-Economic Accounting (SEEA) contabiliza en las cuentas de activos físicos y monetarios cada una de estas tres categorías de capital natural. (United Nations, 2003). Los recursos naturales (biológicos y minerales) y los ecosistemas (aire y agua) se utilizan como materias primas (materia y energía) en la producción de bienes y servicios, y están comprendidos en los bienes de consumo final. Los ecosistemas y la tierra se suelen utilizar como sumidero de los desechos gaseosos, sólidos y líquidos de la actividad humana.
} 
para satisfacer las necesidades de consumo de la población de una economía dada en una medida homogénea. Cada hectárea global de tierra representa la capacidad de bioproducción de recursos naturales (excepto agua dulce) que ingresan al sistema económico, que permiten la producción de bienes y servicios de consumo final y la capacidad de asimilación de desechos (solo la adsorción de $\mathrm{CO}_{2}$ ).

Dado que la huella ecológica es un concepto simple y tiene como principio ser una medida conservadora del impacto ecológico de la actividad humana, en su estimación no se incluye la capacidad de asimilación de desechos distintos al dióxido de carbono (metales pesados, desechos sólidos municipales, tóxicos, aguas residuales) y la demanda de agua dulce. Por lo anterior, la huella ecológica comprende la huella de carbono, es un componente de aquél, pero no la huella hídrica. De aquí se desprende una de las principales desventajas de la huella como indicador de la sustentabilidad, como medida incompleta para medir los impactos de la actividad humana en la biosfera. Para la estimación de la huella hídrica se ha diseñado una metodología de cálculo para tratar de capturar el impacto ecológico de su consumo y contaminación (Hoekstra, 2009). Adicionalmente, se ha desarrollado la huella de carbono de manera independiente al de huella ecológica la cual intenta capturar el potencial de calentamiento de los gases de efecto invernadero en unidades de $\mathrm{CO}_{2}$ equivalente.

Aunque la huella ecológica es un indicador que sintetiza información valiosa para la toma de decisiones de política pública, falla en capturar las distintas dimensiones de la sustentabilidad en los ámbitos sociales, económicos y ecológicos. De acuerdo con Moffatt (2000) y Schaefer et al (2006), las limitaciones de este indicador son: que es un indicador estático, que ignora el papel del cambio tecnológico en el uso de los recursos, deja de lado el uso de recursos que son importantes para el mantenimiento del equilibrio ecológico de los ecosistemas como son los recursos hídricos y los de los océanos, existen recursos cuya capacidad de absorción y regeneración es limitada y que no están representados en la huella ecológica como los metales pesados y radioactivos por un lado y las reservas de combustibles por el otro lado, es una medida que no incorpora consideraciones de equidad intra e inter generacional, entre otras más que mencionan los autores y que por razones de espacio no se mencionan aquí.

Por lo anterior, el análisis presentado en este artículo no pretende ser concluyente sino solo aportar evidencia desde el enfoque de las huellas que junto con otros indicadores permitan abarcar la sustentabilidad de un territorio en sus distintas dimensiones. El análisis de las huellas ecológicas debe acompañarse con información sobre distribución de ingresos, población en pobreza extrema, generación de empleos, uso de agua y descargas de aguas 
residuales, manejo de desechos tóxicos y biológico-infecciosos por mencionar solo algunos de los indicadores que permitirían tener un amplio panorama sobre el tema de la sustentabilidad.

En la estimación de la huella ecológica se puede emplear dos métodos distintos. El primero, hace uso de las estadísticas oficiales de consumo, exportaciones e importaciones, rendimientos de la producción, superficies de tierra según distintos ecosistemas a nivel nacional e internacional (FAO, Sistemas de Cuentas Nacionales, anuarios estadísticos, entre otros) para obtener una medida agregada de la huella ecológica per cápita a nivel nacional (Borucke et al., 2013; Cano, 2004). El segundo hace uso de la información disponible por tipo de bien o servicio y la estimación del ciclo de vida y los requerimientos de energía y materiales de la cuna a la tumba; este método de estimación de la huella es más complicado de llevar a cabo por la dificultad de la delimitación de los requerimientos de los productos y se suele aplicar a un ámbito espacial de menor dimensión incluso al nivel de empresa (Wackernagel et al., 2000; Albino y Kühtz, 2004). Recientemente, y como una extensión del primer enfoque, se han desarrollado propuestas metodológicas para la estimación de la huella ecológica en ámbitos espaciales de menor dimensión al nacional como son las entidades federativas, los municipios y localidades (Cano y Delgado, 2015). El presente trabajo de investigación toma la propuesta metodológica de Cano y Delgado (2015) para la estimación de las huellas ecológicas de las entidades federativas de México.

Para poder determinar la condición de superávit/déficit ecológico es necesario comparar la huella ecológica con la medida de capacidad bioproductiva disponible en hectáreas globales per cápita. Dicho de otra manera, se estima la capacidad de carga de los ecosistemas locales en unidades de tierra (hectáreas globales per cápita), de tal manera que se pueda tener una medida homogénea de la disponibilidad de biocapacidad para contrastarla con la huella ecológica como medida de la demanda de recursos biofísicos del ecosistema local y global. Cuando la demanda es superior a la oferta de biocapacidad, se dice que se incurre en déficit ecológico, es decir, la economía de un territorio está viviendo a expensas de la biocapacidad de otros territorios. Y si la demanda es inferior a la oferta, se incurre en un superávit ecológico, es decir, la economía está viviendo dentro de los límites de sus recursos biofísicos y en los límites de la capacidad de los ecosistemas locales. En este trabajo, se estiman las capacidades de carga de las economías de las entidades federativas de México, basándose en la propuesta de (Borucke et al., 2013; Cano, 2004).

\subsection{Literatura sobre huellas ecológicas}

La literatura sobre huellas ecológicas a nivel internacional es amplia y abundante. En este conjunto de trabajos, podemos mencionar a Bicknell et al 
(1998), Hoekstra (2009), Galli et al (2011), Wiedmann et al (2006), Ewing et al (2012), Wiedmann (2009), Cano (2004), Turner et al (2007), Hubacek y Giljum (2003), entre otros. En México, la literatura sobre huellas ecológica es limitada, se han publicado muy pocos trabajos en esta línea de investigación. Los trabajos publicados se centran en la estimación puntual de la huella ecológica o variantes de la misma acerca de productos, servicios y actividades o de regiones en particular. En el trabajo de Cornejo y Chávez (2013) se estima la huella de carbono de la actividad de avistamiento de ballenas en las Islas Marietas en Nayarit, México. Por su parte, Ríos et al (2015), determinan la huella hídrica azul en los cultivos forrajeros del distrito rural 017 de la comarca lagunera en México, de acuerdo con sus resultados, la producción de maíz y sorgo forrajero en la región resultó altamente eficiente y productiva en comparación con los demás cultivos forrajeros lo que se tradujo en una menor huella hídrica azul. Bueno et al (2019), estiman la huella hídrica de la zona costera de San Blas, México. Vazquez y Lambarri /2017) hacen un análisis de la huella hídrica en determinadas regiones del país, aquella de uso doméstico y productos agrícolas, así como un panorama amplio sobre los componentes de la huella hídrica y sus implicaciones a nivel mundial.

A diferencia de los trabajos referidos con anterioridad, el método propuesto por Cano y Delgado (2015) permite estimar la huella ecológica a nivel subnacional, haciendo uso de la información oficial sobre huellas ecológicas nacionales. Una de las principales ventajas de este método es que al aplica un método estadístico estándar -análisis de componentes principales- para obtener la huella ecológica de espacios subnacionales. Lo anterior garantiza la comparabilidad de resultados entre regiones a nivel nacional. Este es la principal ventaja de dicho método además de que permite identificar las variables que tienen el mayor impacto en la huella ecológica de un territorio dado.

\section{Metodología}

Este trabajo parte de la información disponible sobre huellas ecológicas nacionales y estadísticas oficiales de la actividad económica a nivel entidad federativa. Se hace uso de la propuesta metodológica de Cano y Delgado (2015) para la estimación de huellas ecológicas a una escala espacial local o regional, de menor nivel que las estimaciones convencionales sobre huellas ecológicas. El método está basado en el Análisis de Componentes Principales con el fin de estimar la escala de la actividad humana en las entidades federativas de México.

La información más reciente sobre huellas ecológicas nacionales corresponde al año 2013. En este año, la huella ecológica nacional ascendió a 2.7 hectáreas globales per cápita (gha/pc) (Global Footprint Network). Con base en este dato 
y en el método de Análisis de Componentes Principales, se distribuyó este valor entre las 32 entidades federativas de México. Los factores de ponderación que sirvieron de base para la distribución de la huella entre las entidades federativas de México fueron los asociados al primer componente lo cual explica la mayor parte de la varianza de las variables incluidas en el análisis. Las variables utilizadas en el estudio son: Producto Interno Bruto (PIB) en millones de pesos a precios corrientes (Sistema de Cuentas Nacionales, INEGI), residuos sólidos urbanos en miles de toneladas anuales (SEDESOL), vehículos de motor registrados en circulación (Estadísticas de vehículos de motor registrados en circulación, INEGI), consumo de energía eléctrica en gigawatts por hora (Comisión Federal de Electricidad), cuartos de hospedaje (Secretaría de Turismo e INEGI), establecimientos (Censo Económico, INEGI) y viviendas particulares habitadas (Censo de Población y Vivienda, INEGI).

El método para la estimación de las huellas ecológicas de las entidades federativas de México está conformado por un conjunto de etapas. Primeramente, se parte de un conjunto de $p$ variables, $X_{1}, X_{2}, \ldots, X_{p}$, en niveles. A partir de este conjunto de variables, se estiman los componentes principales del conjunto de datos en el programa STATAC. Es decir, se hace la estimación de los eigenvalores y eigenvectores del análisis de componentes principales ${ }^{3}$. Una vez que se calculan los componentes, se toma el componente con la mayor varianza (eigenvalor) y los coeficientes (eigenvectores) $\left(u_{1 i}\right)$ de este componente se multiplican con las variables asociadas a cada entidad federativa. El valor de $Y_{l i}$ sirve de ponderador para estimar la huella ecológica de cada una de las entidades federativas de México. Esto es, en términos algebraicos para el componente uno, se tiene:

$$
Y_{1 i}=u_{11} X_{1 i}+u_{12} X_{2 i}+\cdots+u_{1 p} X_{p i}
$$

Donde $i=1, \ldots, n$ es el número de entidades federativa para un conjunto de $p$ variables.

En términos matriciales, para el conjunto de $n$ observaciones (entidades federativas) del componente 1 , se puede representar de la siguiente forma:

$$
\left(\begin{array}{c}
Y_{11} \\
Y_{12} \\
\cdots \\
Y_{1 n}
\end{array}\right)=\left(\begin{array}{cccc}
X_{11} & X_{21} & \cdots & X_{p 1} \\
X_{12} & X_{22} & \cdots & X_{p 2} \\
\cdots & \cdots & \cdots & \cdots \\
X_{1 n} & X_{2 n} & \cdots & X_{p n}
\end{array}\right)\left(\begin{array}{c}
u_{11} \\
u_{12} \\
\cdots \\
u_{1 p}
\end{array}\right)
$$

\footnotetext{
${ }^{3}$ Los eigenvalores son las varianzas de los componentes principales y los eigenvectores son los coeficientes que integran a cada componente. Los eigenvectores se pueden representar como una combinación lineal de las $p$ variables del conjunto de datos.
} 
Dado que la media de $Y_{1 i}, i=1, \ldots, n$ es una magnitud distinta de uno, se hace un cambio de escala en la cual la media tenga valor 1 y desviación estándar de 1 de tal manera que estos factores transformados se utilizan finalmente como ponderadores normalizados $Z_{l i}$ para estimar la huella ecológica de las entidades federativas de México en hectáreas globales. Con los ponderadores normalizados y el dato de la huella ecológica total de México, la cual asciende a $\mathrm{HE}=334,098,302$ hectáreas globales para el año 2013 según la Footprint Network, se estima la huella ecológica en hectáreas globales (gha) por entidad federativa $\left(H E_{\mathrm{i}}\right)$. La huella en términos per cápita (gha/pc) se estima dividiendo la huella en hectáreas globales de cada entidad federativa por el total de la población respectiva. La media de las huellas ecológicas por entidad federativa permite obtener la huella ecológica de México, la cual asciende a $2.6 \mathrm{gha} / \mathrm{pc}$ una diferencia de una décima con respecto a aquella reportada por Footprint Network para el año 2013, la cual asciende a 2.7 gha/pc. La diferencia puede deberse a los redondeos de las huellas ecológicas estimadas de las entidades federativas.

$$
H E_{i}=H E\left(Z_{1 i}\right)
$$

Además, se realiza la estimación de la oferta de recursos naturales y los servicios de asimilación de desechos de los ecosistemas de las entidades federativas de México en unidades de hectáreas globales per cápita. Es decir, de la capacidad bioproductiva disponible local en una medida homogénea como lo son las hectáreas globales per cápita. La información sobre superficie territorial según tipo de uso de suelo se tomó de los Inventarios Estatales Forestales y de Suelos de los años 2013 y 2014 (SEMARNAT-CONAFOR). En las estimaciones de la capacidad bioproductiva de cada entidad federativa, se necesario contar con los datos de la superficie territorial en hectáreas de las siguientes categorías: agrícola, pastizales, área forestal y zonas urbanas.

Los pasos para la estimación de la capacidad bioproductiva disponible per cápita $(C B)$ por entidad federativa $i$ se indican a continuación: las hectáreas de superficie $(h a)$ por tipo de uso de suelo $j$ se dividen por la población (pob) para obtener el per cápita disponible por tipo de uso de suelo $j$. A su vez, se multiplica por el factor de rendimiento $(f r)$ según $j$ para obtener el equivalente en hectáreas mundiales per cápita por tipo de uso de suelo y finalmente se multiplica por el factor de equivalencia $(f e)$ según $j$ para obtener el valor expresado en hectáreas globales per cápita (Borucke et al., 2013; Cano, 2004). La capacidad bioproductiva disponible local se estima para cada una de las entidades federativas $i$. La fórmula se expresa de la siguiente manera:

$$
\begin{aligned}
& C B_{i}=\sum_{j=1}^{4}\left[\left(h a_{i j} / p o b_{i}\right) * f r_{i j} * f e_{i j}\right] \\
& i=1, \ldots, 32, j=1, \ldots, 4
\end{aligned}
$$


Los factores de rendimiento utilizados en la estimación de la capacidad de carga de la superficie agrícola y forestal se estiman dividiendo la producción (agrícola o forestal) local (ton/ha) y la producción mundial (agrícola o forestal) $(t o n / h a)$. Es decir, el cociente del rendimiento medio local y el rendimiento medio mundial ${ }^{4}$. En relación con la superficie destinada a pastos, el factor de rendimiento se obtiene al dividir la producción local de carne (bovino, caprino y ovino) y leche ambos en gigajoules por hectárea $(G j / h a)$ y la correspondiente a la producción mundial en $(G j / h a)$.). El factor de rendimiento y el factor de equivalencia de la superficie de las zonas urbanas es equivalente al factor de rendimiento y factor de equivalencia de las áreas agrícolas (Cano, 2004; Borucke et al., 2013; Wackernagel, 1994).

Por otra parte, se estimó el factor de equivalencia de los diferentes tipos de uso de suelo. El Este factor permite obtener una medida en hectáreas comparable a aquella obtenida para la huella ecológica, con el fin de contrastar ambas y con ello obtener el déficit/superávit ecológico de una entidad en particular. Por lo anterior, el factor varía de acuerdo con el tipo de uso de suelo y por año. En particular, el factor de equivalencia permite obtener el equivalente de las hectáreas globales a partir de la información de las hectáreas mundiales por tipo de uso de suelo. De manera más general, de acuerdo con Borucke et al (2013) la lógica del factor de equivalencia consiste en permitir obtener ponderaciones de la capacidad inherente de cada tipo de área de tierra para generar recursos biológicos útiles a la actividad humana. Es importante destacar que la estimación no se basa en la capacidad actual para producir biomasa sino en la capacidad inherente de generación de biomasa de cada tipo de tierra.

Con relación a los factores de equivalencia, éstos se estimaron con base en el siguiente procedimiento. En primer lugar, se tomó el valor del índice de adecuación mundial reportado en Borucke et al., (2013). Los índices que se utilizaron fueron los siguientes: agrícola 0.9 , forestal 0.5 , pastizal 0.1 y por convención metodológica para la zona urbana se toma el mismo valor para las áreas agrícolas. Este índice de adecuación sirvió para estimar las hectáreas disponibles ajustadas ( $h a / p c$ ajustadas) por tipo de uso de suelo $j$. Después, se obtuvieron las hectáreas relativas como el cociente de las hectáreas ajustadas de cada categoría con relación a la categoría agrícola que sirve de base de comparación. El factor de equivalencia para cada tipo de uso de suelo entonces es la división de las hectáreas relativas correspondientes a cada tipo y un valor dado por un cociente que expresa las hectáreas ajustadas promedio ponderadas por su participación en el total y el total de hectáreas ajustadas (Cano, 2004). El factor de equivalencia para cada tipo de uso de suelo se estimó por entidad

\footnotetext{
${ }^{4}$ Para la estimación del rendimiento medio local y mundial solo se tomaron los datos de la producción de maíz, trigo y centeno.
} 
federativa. La superficie forestal para extracción de recursos forestales y la que corresponde a la captura de carbono es la misma.

Por otra parte, se estima el superávit y déficit ecológico como la diferencia entre la Capacidad Bioproductiva (CB) y la Huella Ecológica (HE) ambas en $\mathrm{gha} / \mathrm{pc}$. El déficit ecológico se presenta cuando la huella ecológica es mayor a la capacidad bioproductiva local, es decir, cuando la demanda de recursos y servicios del ecosistema es mayor a la capacidad de carga del ecosistema local. El superávit ecológico se presenta cuando la capacidad bioproductiva local es mayor a la huella ecológica, en esta situación, la oferta de recursos y servicios ecosistémicos locales es mayor a la demanda bioproductiva de las actividades económicas y la población y puede ser satisfecha en su totalidad por los servicios y recursos de los ecosistemas locales. La fórmula para estimar el déficit/superávit es la siguiente:

$$
\begin{aligned}
& \text { Superávit }=C B_{i}-H E_{i}>0 \\
& \text { Déficit }=C B_{i}-H E_{i}<0
\end{aligned}
$$

\section{Huella ecológica de las entidades federativas}

En el tabla 1 y figura 1 se presentan los resultados de las estimaciones de la huella ecológica. En el anexo 1 se pueden encontrar las principales características de las variables, matriz de correlación, los componentes principales y la prueba de Kaiser-Meyer-Olkin. Los resultados indican que Tlaxcala es la entidad federativa con la huella ecológica más baja ( $1.4 \mathrm{gha} / \mathrm{pc})$ y la ciudad de México con la huella ecológica más alta (4.7 gha/pc). Le sigue en importancia en orden descendente, Campeche (4.2 gha/pc), Nuevo León (3.8 gha/pc), Jalisco (3.2 gha/pc), Michoacán (3.1 gha/pc), Chihuahua (3.0 gha/pc), Baja California y Tamaulipas (2.8 gha/pc), Baja California Sur, Sinaloa, Sonora y Quintana Roo con una huella de ( $2.7 \mathrm{gha} / \mathrm{pc})$. Estas entidades federativas tienen una huella superior o igual a la huella del país. Todas las demás entidades, tienen una huella ecológica de menor valor ${ }^{5}$.

El desarrollo económico, social y ambiental en las entidades federativas es diverso y está en función de distintos factores que se presentan a nivel local. Los factores que destacan son el tamaño de la población, el consumo de energía eléctrica, el tamaño de la economía medida a través del PIB estatal, los residuos sólidos urbanos, vehículos de motor en circulación, cuartos de hospedaje, número de establecimientos y viviendas particulares. Las políticas de desarrollo sustentable deben considerar esta diversidad a nivel territorial para

\footnotetext{
${ }^{5}$ Según la Global Footprint Network la huella ecológica de México en el 2013 fue de 2.7 gha/pc. En este trabajo de investigación, el promedio de la huella ecológica de las 32 entidades federativas resultó ser de 2.6 gha/pc para el mismo año. Los autores del trabajo consideramos que la diferencia en el decimal se debe a razones de redondeo de las cifras.
} 
el diseño de estrategias y acciones a nivel regional tanto a mediano, como a largo plazo con el fin de mitigar los impactos de las actividades humanas en los sistemas naturales locales, pero también en los globales. Los recursos naturales, los ecosistemas y la tierra a nivel local deben protegerse para que tanto los servicios (de asimilación de desechos, de soporte de vida, paisaje para la recreación), recursos, energía y materias primas que proporcionan a la población puedan mantenerse a perpetuidad para garantizar el bienestar de las generaciones presentes y futuras.

Como podemos observar en el figura 2, la huella ecológica tiene una alta relación con el tamaño de la economía, medido por el PIB. A mayor tamaño de la economía, mayor es la huella ecológica de la entidad. Aunque la relación no es perfecta. El tamaño de la economía es una medida del uso de recursos naturales, factores productivos (trabajo, capital físico) y recursos financieros (monetarios), que se movilizan para producir bienes y servicios que se ponen a disposición de la población. El consumo de la población demanda recursos de la biosfera (recursos naturales y capacidad de asimilación de desechos) a nivel local como base para su continua expansión.

Este hallazgo conduce a afirmar que, si una economía crece y, por lo tanto, aumenta de tamaño, mayor es el consumo de recursos y servicios de la biosfera a nivel local. Si las condiciones descritas anteriormente se mantienen sin cambio, entonces el consumo de la biocapacidad podría llegar a ser mayor a la tasa de regeneración de los recursos naturales, entonces se prevé un escenario de disminución en el acrevo de capital natural disponible para proveer insumos y materias primas necesarias a la producción, consumo y acumulación de la economía. Y hay mayor riesgo de incurrir en déficit ecológico, una situación en donde la capacidad de carga de los ecosistemas locales y del territorio ha sido rebasada en su totalidad. Esta condición es una situación de desequilibrio ambiental, dado que la economía está demandando recursos a una tasa superior a la capacidad de regeneración de los ecosistemas locales, por lo que la población está viviendo a expensas de las generaciones futuras que aún no han nacido y cuyo nivel de vida dependerá de las condiciones que hayan heredado de las generaciones que le precedieron. 
Tabla 1

Huellas Ecológicas y Capacidad de Carga de las entidades federativas de México, 2013

\begin{tabular}{|l|r|r|r|r|c|c|}
\hline \multicolumn{1}{|c|}{ Entidad } & Z estandar & \multicolumn{1}{c|}{ HE gha } & Población & HE gha/pc & BC gha/pc & Sup $(+) /$ Déf(-) \\
\hline Aguascalientes & 0.30 & $3,090,368$ & $1,308,800$ & 2.4 & 0.5 & -1.9 \\
\hline Baja California & 0.93 & $9,760,339$ & $3,533,722$ & 2.8 & 0.7 & -2.1 \\
\hline Baja California Sur & 0.20 & $2,059,008$ & 750,620 & 2.7 & 1.1 & -1.7 \\
\hline Campeche & 0.37 & $3,856,558$ & 920,041 & 4.2 & 2.1 & -2.1 \\
\hline Chiapas & 0.82 & $8,517,277$ & $5,350,296$ & 1.6 & 1.0 & -0.5 \\
\hline Chihuahua & 1.08 & $11,287,763$ & $3,800,116$ & 3.0 & 2.6 & -0.3 \\
\hline Coahuila & 0.75 & $7,799,938$ & $3,020,585$ & 2.6 & 0.6 & -1.9 \\
\hline Colima & 0.12 & $1,300,601$ & 729,821 & 1.8 & 0.8 & -1.0 \\
\hline Ciudad de México & 4.17 & $43,584,438$ & $9,295,259$ & 4.7 & 0.0 & -4.7 \\
\hline Durango & 0.37 & $3,824,665$ & $1,806,461$ & 2.1 & 3.0 & 0.9 \\
\hline Estado de México & 4.21 & $43,979,646$ & $17,102,988$ & 2.6 & 0.0 & -2.6 \\
\hline Guanajuato & 1.40 & $14,574,543$ & $5,977,931$ & 2.4 & 1.0 & -1.5 \\
\hline Guerrero & 0.76 & $7,888,278$ & $3,682,946$ & 2.1 & 0.8 & -1.3 \\
\hline Hidalgo & 0.69 & $7,224,162$ & $2,933,029$ & 2.5 & 1.0 & -1.5 \\
\hline Jalisco & 2.45 & $25,616,815$ & $8,091,837$ & 3.2 & 1.5 & -1.6 \\
\hline Michoacán & 1.39 & $14,529,350$ & $4,734,422$ & 3.1 & 1.2 & -1.9 \\
\hline Morelos & 0.40 & $4,191,951$ & $1,958,800$ & 2.1 & 0.4 & -1.8 \\
\hline Nayarit & 0.23 & $2,405,849$ & $1,231,603$ & 2.0 & 1.7 & -0.2 \\
\hline Nuevo León & 1.87 & $19,548,702$ & $5,164,127$ & 3.8 & 0.5 & -3.3 \\
\hline Oaxaca & 0.65 & $6,791,727$ & $4,137,777$ & 1.6 & 0.7 & -0.9 \\
\hline Puebla & 1.36 & $14,166,383$ & $6,341,535$ & 2.2 & 0.5 & -1.8 \\
\hline Querétaro & 0.45 & $4,656,844$ & $2,031,648$ & 2.3 & 0.7 & -1.6 \\
\hline Quintana Roo & 0.40 & $4,136,910$ & $1,552,000$ & 2.7 & 0.2 & -2.5 \\
\hline San Luis Potosí & 0.71 & $7,367,280$ & $2,824,136$ & 2.6 & 0.5 & -2.1 \\
\hline Sinaloa & 0.80 & $8,366,489$ & $3,064,695$ & 2.7 & 4.6 & 1.8 \\
\hline Sonora & 0.76 & $7,917,729$ & $2,980,193$ & 2.7 & 4.0 & 1.4 \\
\hline Tabasco & 0.57 & $5,956,462$ & $2,439,886$ & 2.4 & 0.9 & -1.6 \\
\hline Tamaulipas & 0.95 & $9,968,266$ & $3,617,601$ & 2.8 & 2.7 & -0.1 \\
\hline Tlaxcala & 0.18 & $1,853,088$ & $1,298,838$ & 1.4 & 0.4 & -1.0 \\
\hline Veracruz & 1.88 & $19,657,663$ & $8,280,899$ & 2.4 & 1.8 & -0.6 \\
\hline Yucatán & 0.48 & $5,049,370$ & $2,157,339$ & 2.3 & 0.3 & -2.1 \\
\hline Zacatecas & 0.30 & $3,169,841$ & $1,620,163$ & 2.0 & 0.5 & -1.5 \\
\hline País & & & & 2.6 & 1.2 & -1.4 \\
\hline Fuente: Estimacis & \\
\hline
\end{tabular}

Fuente: Estimaciones propias 


\section{Figura 1}

Huellas ecológicas de las entidades federativas de México, 2013

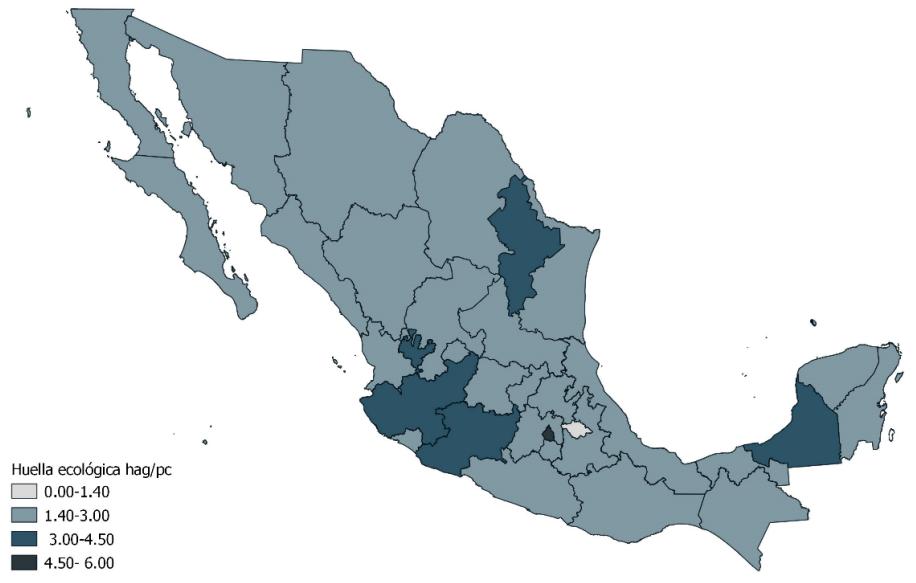

Fuente: elaboración propia en QGIS 3.0.3

Figura 2

Huellas Ecológicas y PIB (millones de pesos a precios del 2013) de las entidades federativas de México

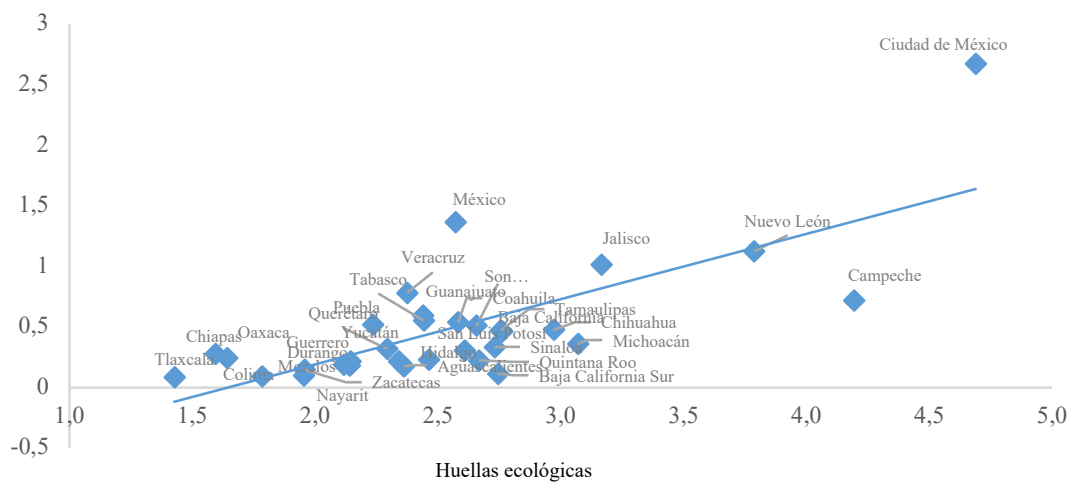

Fuente: Elaboración propia con base en resultados de huellas ecológicas e INEGI 


\section{Biocapacidad y déficit ecológico en las entidades federativas}

En este apartado se estima la capacidad bioproductiva disponible en las entidades federativas de México ${ }^{6}$. Es decir, la oferta de recursos naturales y servicios de asimilación de desechos del ecosistema local en unidades de hectáreas globales per cápita. Los resultados de la biocapacidad se contrastan con aquellos de la huella ecológica para obtener el superávit o déficit ecológico por entidad federativa. En el anexo 2 se presentan los resultados de los factores de rendimiento y equivalencia por tipo de uso de suelo y en el anexo 3 los tipos de uso de suelo en hectáreas.

El análisis de los resultados se presenta en el tabla 1 y figura 3 . Se observa que 29 entidades federativas presentan déficit ecológico, esto es, la demanda de biocapacidad de la población supera la oferta de recursos y servicios ecológicos a nivel local por lo que se está presentando un quiebre ecológico. La escala de actividad económica ha rebasado los límites de los ecosistemas locales en la provisión de energía y materiales para el sostenimiento del sistema económico y en la absorción de las emisiones de carbono que emiten las actividades en conjunto. El déficit ecológico de las economías de las entidades federativas pone en riesgo el acervo de capital natural disponible y si esta situación se mantiene por un largo periodo podría conducir a la degradación progresiva del mismo hasta su agotamiento definitivo. La riqueza natural de los ecosistemas locales no está siendo administrada de manera sostenible, por lo que se corre el riesgo de colapso de los sistemas naturales y del sistema económico cuya reproducción continua se apoya en el primero.

Destaca el caso de la Ciudad de México con una huella ecológica de $4.7 \mathrm{gha} / \mathrm{pc}$ $\mathrm{y}$ una oferta de biocapacidad disponible aproximadamente de cero que contribuyen a un déficit ecológico de $4.7 \mathrm{gha} / \mathrm{pc}$. La oferta de biocapacidad es muy cercana a cero, debido a diversos factores que han contribuido a la degradación de los servicios de los ecosistemas locales. La alta densidad de población de 5,967 hab $/ \mathrm{km}^{2}$ (INEGI, 2010), la mayor del país, contribuye a que los recursos y servicios biológicos a nivel local no puedan cubrir la sobredemanda de alimentos, recursos biológicos y absorción de desechos que se generan por el excesivo nivel de consumo agregado de la población local. La demanda de suelo para uso urbano ha contribuido a la disminución de la bioproductividad local, al uso intensivo del suelo productivo y no productivo y a su degradación por sobreexplotación.

\footnotetext{
${ }^{6}$ En la estimación de la capacidad de carga disponible o capacidad bioproductiva por entidad federativa, se aplicó la fórmula señalada en el apartado metodológico. Se tuvieron que ajustar los resultados por un factor de escala para que el resultado agregado a nivel país (el promedio de todas las entidades federativas) coincidiera con el valor reportado por la Global Footprint Network que corresponde a una $\mathrm{CB}=1.2 \mathrm{gha} / \mathrm{pc}$. El factor de escala consistió en multiplicar la $\mathrm{CB}$ por un factor de 2 .
} 
El déficit ecológico no solo tiene implicaciones ambientales sino también sociales y éticas para las generaciones futuras y para otros territorios. Los conflictos sociales por el control de los recursos naturales (tierra, agua, bosques) entre regiones o ciudades están surgiendo con más fuerza en años recientes alimentados por la creciente escasez de aquéllos. Dicha escasez es intensificada por los efectos del cambio climático en los ecosistemas locales que conduce a una mayor degradación ambiental y pérdida de biodiversidad. La población que depende de los recursos de los ecosistemas para su sustento diario (leña, carbón vegetal, agua, caza, pesca ribereña, plantas y vegetales silvestres, entre otros) son los más vulnerables a la creciente escasez lo que agudiza aún más los conflictos por el control de los recursos naturales.

La sobredemanda de recursos biofísicos de las entidades federativas con déficit ecológico presumiblemente está siendo satisfecha con los recursos biológicos de otras áreas que presentan una condición de superávit ecológico, posiblemente a través del comercio de bienes y servicios con otros estados que presentan dicha condición, como es el caso de Sinaloa, Durango y Sonora en México; y a través del comercio internacional con países como Canadá que presentan un superávit ecológico de 8.49 gha/pc. La apropiación de los recursos que pertenecen a otras áreas, entidades federativas y países a través del consumo de bienes importados que para su producción incorporan recursos bioproductivos, está contribuyendo a acrecentar la inequidad en la distribución de los recursos de la biosfera que se concentran en las áreas que presentan un proceso de desarrollo que no está siendo sustentable a escala local.

Así mismo, la población actual está viviendo a expensas del bienestar de las generaciones futuras, porque está consumiendo los recursos y servicios de la biosfera a una tasa que pone en riesgo la disponibilidad futura de los mismos para su consumo por la población que aún no nace. Las implicaciones éticas no son menos importantes que las sociales y requieren atención prioritaria para evitar que la población actual expolie los recursos que no le pertenecen de manera exclusiva. La civilización actual debe extraer lecciones de las civilizaciones antiguas que lograron desarrollar sus economías en plena armonía con el entorno natural y gracias a lo cual, las generaciones del presente están disfrutando de los recursos naturales que conservaron y nos legaron.

Por otra parte, destacan los casos de Sinaloa, Durango y Sonora con oferta neta positiva de biocapacidad. El caso de Durango con un superávit de 0.9 gha/pc y Sonora con $1.4 \mathrm{gha} / \mathrm{pc}$. Estas dos entidades federativas presentan una densidad de población de 14 y $16 \mathrm{hab} / \mathrm{km}^{2}$ respectivamente, detrás de Baja California Sur con una densidad de $10 \mathrm{hab} / \mathrm{km}^{2}$. La baja densidad poblacional es un factor que contribuye a la baja demanda de recursos y servicios para consumo el cual aún está dentro de los límites de las disponibilidades locales. Además, la escala de la actividad económica de ambas entidades se desarrolla 
dentro de los límites de la capacidad de carga de la biosfera local. Por su parte, el estado de Sinaloa con un superávit de $1.4 \mathrm{gha} / \mathrm{pc}$, presenta una densidad poblacional $\left(52 \mathrm{hab} / \mathrm{km}^{2}\right)$ muy cercana al promedio del país $\left(61 \mathrm{hab} / \mathrm{km}^{2}\right)$ (INEGI, 2010), por lo que no es un factor explicativo de esta condición. En su caso, el estado presenta altos niveles de rendimientos agrícolas y pecuarios que destacan no solo a nivel nacional sino también a nivel mundial, por lo que la oferta bioproductiva local está superando la demanda de consumo de la población local. Sin embargo, aun cuando el estado Sinaloa, pero también Sonora y Durango, presentan una condición de superávit ecológico, no debe obviarse otros elementos importantes que no están siendo considerados en la metodología de las huellas ecológicas y capacidad de carga local, como es la contaminación de agua, distribución del ingreso, por mencionar algunos, en un análisis más integral del desarrollo sustentable de las economías locales.

\section{Figura 3 \\ Déficit/Superávit ecológico}

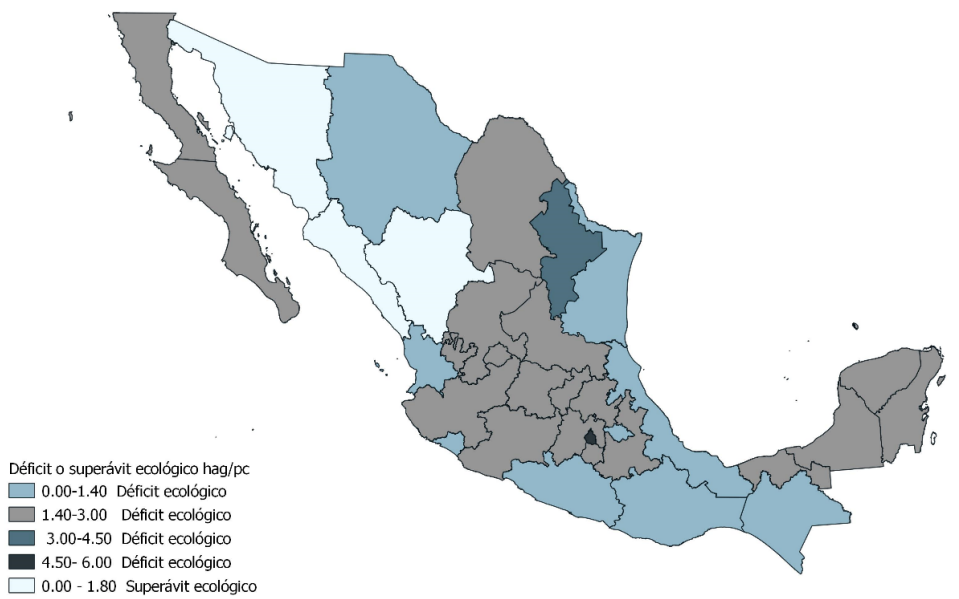

Fuente: elaboración propia en QGIS 3.0.3

\section{Conclusiones}

El desarrollo económico en la mayor parte de las entidades federativas no está siendo sustentable. Se llegó a la conclusión anterior, con base en los resultados obtenidos de la huella ecológica, capacidad de carga disponible y la estimación del superávit/déficit ecológico en cada una de las 32 entidades federativas del país. Los resultados sugieren que el modelo de desarrollo implementado en 
México y en el nivel local (excepto para Sonora, Durango y Sinaloa) no conduce a un uso sustentable de los recursos naturales y de los servicios de los ecosistemas y que, de continuarse con este modelo, se corre el riesgo de un colapso de los sistemas que le dan sustento a la vida. Se requiere empezar a considerar a la naturaleza como un sistema que no se puede disociar del sistema económico-social y que para el sostén de ésta se requiere mantener un acervo de capital natural que permita la reproducción económica de manera indefinida para bienestar de las generaciones actuales y futuras.

La planeación del desarrollo a nivel local en México debe incorporar el elemento de la sostenibilidad y que el desarrollo es un proceso que implica la interacción de las esferas económicas, sociales y ambientales. La promoción de una sola dimensión en detrimento de las otras dos no conduce al desarrollo sustentable, como ha ocurrido actualmente dado que solo se ha favorecido el factor económico (crecimiento económico y generación de riqueza) a costa del deterioro ecológico y la polarización de la población debido al ensanchamiento de brechas entre ricos y pobres. Los diseñadores de política pública deben promover el cambio de paradigma en los procesos de la planeación del desarrollo para pasar de una planeación cortoplacista economicista a una de mediano y largo plazo enfocada en el equilibrio dinámico de los sistemas económicos-sociales y ambientales dentro de los límites físicos de los ecosistemas.

Aunque la huella ecológica y la capacidad de carga representan índices que sintetizan información valiosa para la toma de decisiones de política pública, aún son indicadores que no logran capturar las otras dimensiones de la sustentabilidad como la social, económica y cuestiones en materia de manejo ambiental. Por lo anterior, el análisis presentado en este artículo debe complementarse con información sobre distribución de ingresos, población en pobreza extrema, generación de empleos, uso de agua y descargas de aguas residuales, manejo de desechos tóxicos y biológico-infecciosos por mencionar algunos temas a considerar en los análisis de sustentabilidad. Al menos, para comenzar en la dirección correcta, y como un primer paso en este sentido, los diseñadores de política pública deben dar los pasos necesarios para incorporar la huella ecológica como indicador de la gestión de la sustentabilidad en los procesos de planeación del desarrollo local. Además, se debe pasar de un enfoque de planeación de corto plazo, como se ha comentado con anterioridad, a uno enfocado a periodos temporales que comprendan una visión de mediano y largo plazos en línea con los procesos de planeación sustentable.

Actualmente, los diseñadores de políticas públicas pueden apoyarse en la agenda de desarrollo basada en los ODS de la ONU como marco para orientar las acciones a emprender en cada territorio de acuerdo con las particularidades de los sistemas y estructuras económicas y sociales en el nivel local. En este 
sentido, la planeación sustentable del territorio puede servir de base para adaptar las acciones de la nueva agenda de desarrollo a una escala subnacional de acuerdo con la visión del desarrollo local de todos los actores del territorio en dos vertientes: modelo de sustentabilidad débil o fuerte.

Las acciones de planeación con base en el principio de sustentabilidad fuerte deben incorporar todas aquellas que son necesarias para organizar y administrar los recursos del territorio con base en el principio de precaución y de acuerdo con los postulados de la escuela de la economía ecológica. De acuerdo con el principio de precaución, las acciones a emprender comprenden aquellas que evitan daños irreversibles a los recursos naturales que en esencia son insustituibles, es decir, que no pueden ser sustituidos por otros tipos de materiales no naturales. En este marco, las acciones de protección y apoyo a los sistemas agrícolas tradicionales con manejo agroecológico (milpa) como alternativa a los sistemas de producción de monocultivo para la producción de alimentos, se enmarcan en este modelo. Otras acciones a considerar es el incremento del número de hectáreas de áreas naturales protegidas, protección de especies animales y vegetales en peligro de extinción, creación de bancos de germoplasma, entre otros. Por otra parte, las acciones de establecimientos de explotaciones comerciales forestales, pesqueras, agrícolas con base en los parámetros de rentabilidad de análisis costo-beneficio, gestión de recursos naturales con base en los parámetros de valoraciones monetarias de los recursos naturales, es decir, con base en los postulados de la economía ambiental son acordes a los principios de sustentabilidad débil. Estos son algunos ejemplos de las acciones a emprender por los gobiernos locales, a manera de ejemplificación ya que no es el fin de este trabajo establecer una lista exhaustiva de acciones, el cual debería ser retomado como una línea de investigación a desarrollar en trabajos futuros.

\section{Referencias}

[1] Albino, V., \& Kühtz, S. (2004). Enterprise input-output model for local sustainable development - the case of a tiles manufacturer in Italy. Resources, Conservation and Recycling, 41(3), 165-176. doi:10.1016/j.resconrec.2003.09.006

[2] Albornoz, L. (2015). Sustentabilidad económica, social y ambiental en el marco de una matriz de contabilidad social híbrida para el estado de Yucatán, México, tesis de doctorado por la Universidad de Sevilla, España. Disponible en: https://idus.us.es/handle/11441/38376

[3] Bicknell, K., Ball, R., Cullen, R. y Bigsby, H. (1998), New methodology for the ecological footprint with an application to the New Zealand economy, Ecological Economics, 27, 149- 160.

[4] Borucke, M., Moore, D., Cranston, G., Gracey, K., Iha, K., Larson, J., Lazarus, E., Morales, J.C., Wackernagel, M., y Galli, A. (2013). Accounting for demand and supply of the biosphere's regenerative capacity: The National Footprint 
Accounts'underlying methodology and framework, Ecological Indicators, 24, 518-533.

[5] Bueno, S. E., S. Marceleño, O. Nájera, R. de Haro (2019), Implementación del método de escasez en la determinación de la huella hídrica en la zona costera de San Blas, México, Tecnura, 23(62), https://doi.org/10.14483/22487638.15796

[6] Cano, A. (2004), Economía y sostenibilidad en las grandes aglomeraciones urbanas: una aproximación al cálculo de la huella ecológica de Sevilla y su área metropolitana, Sevilla Global, 316 páginas.

[7] Cano, A. y Delgado, M. (2015), Local ecological footprint using principal component analysis: a case study of localities in Andalusia (Spain), Ecological Indicators, vol. 57, october 2015, pp. 573-579

[8] Comisión Federal de Electricidad, Sistema de Información Energética, disponible en: http://sie.energia.gob.mx/

[9] Cornejo, J. L. y R. M., Chávez (2013), la huella de carbono de la observación de ballena jorobada (Megaptera novaeangliae) en las islas Marietas, Nayarit, México, Revista Internacional de Contaminación Ambiental, 30(1): 121-130.

[10] Ewing, B. R., Hawkins, T. R., Wiedmann, T. O., Galli, A., Ertug Ercin, A., Weinzettel, J., y Steen-Olsen, K. (2012). Integrating ecological and water footprint accounting in a multi-regional input-output framework. Ecological Indicators, 23(0), 1-8. doi:10.1016/j.ecolind.2012.02.025

[11] FAOSTAT. Food and Agriculture Organization of the United Nations. Statistic Division. FAOSTAT DATABASE. Disponible en: http://faostat3.fao.org/home/E

[12] Footprint Network (2018), National Footprint Accounts 2018 edition, http://data.footprintnetwork.org/\#/

[13] Galli, A., Wiedmann, T., Ercin, E., Knoblauch, D., Ewing, B. y Giljun, S. (2011), Integrating Ecological Carbon and Water Footprint: Defining the "Footprint Family" and its application in tracking human pressure on the Planet. OPEN: EU project deliverable http://www.oneplaneteconomynetwork.org/

[14] Hoekstra, A. Y. (2009), Human appropriation of natural capital: a comparison of ecological footprint and water footprint analysis. Ecological Economics, 68, 1963-1974.

[15] Hubacek, K., y Giljum, S. (2003). Applying physical input-output analysis to estimate land appropriation (ecological footprints) of international trade activities. Ecological Economics, 44(1), 137-151. doi:10.1016/S09218009(02)00257-4

[16] INEGI, Varios documentos. Disponible en: www.inegi.org

[17] Moffatt, I. (2000). Ecological footprints and sustainable development, Ecological Economics 32(2000): 359-362

[18] ONU (1987). Informe de la Comisión Mundial sobre el Medio Ambiente y el Desarrollo, Organización de las Naciones Unidas. Disponible en: www.un.org

[19] Ríos, J.L., M. Torres, R. Castro, M.A. Torres, J. Ruiz (2015), Determinación de la huella hídrica azul en los cultivos forrajeros del DR-017, Comarca Lagunera, México, Revista de la Facultad de Ciencias Agrarias, Universidad Nacional del Cuyo, Mendoza, Argentina, 47(1): 93-107.

[20] Rodríguez, C. (2004). Sistema híbrido para el análisis de las relaciones entre el medioambiente, la economía y la sociedad. Aplicación para el año 2000 al 
recurso agua y las emisiones a la atmósfera en España. Tesis de doctorado, Universidad de Sevilla, España.

[21] Schaefer, F., U. Luksch, N. Steinbach, J. Cabeca and J. Hanauer, Ecological Footprint and Biocapacity, the world's ability to regenerate resources and absord waste in a limited time period, Working papers and studies, Luxembourg: office for official publications oth the European Communities.

[22] SEDESOL, Dirección General de Equipamiento e Infraestructura en Zonas UrbanoMarginadas. Fecha de consulta: 27 de junio de 2016.

[23] SAGARPA, Sistema de Información Agroalimentaria y Pesquera, disponible en: https://nube.siap.gob.mx/cierreagricola/

[24] SEMARNAT-CONAFOR (2015). Colección de Inventarios Estatales Forestales y de Suelos 2013-2014. México: Secretaría de Medio Ambiente y Recursos Naturales y Comisión Nacional Forestal.

[25] Turner, K., Lenzen, M., Wiedmann, T., y Barrett, J. (2007). Examining the global environmental impact of regional consumption activities — part 1: A technical note on combining input-output and ecological footprint analysis. Ecological Economics, 62(1), 37- 44. doi:10.1016/j.ecolecon.2006.12.002

[26] United Nations (2003), Integrated environmental and economic accounting 2003, United Nations, European Commission, International Monetary Fund, Organization for Economic Co-operation and Development World Bank.

[27] Vázquez del Mercado, R. y J. Lambarri (2017). Huella hídrica en México: análisis y perspectiva, Jiutepec, Morelos, México: Instituto Mexicano de Tecnología del Agua. 255 pp.

[28] Wackernagel, M. (1994), Ecological Footprint and Appropriated carrying capacity: a tool for planning toward sustainability, Thesis submitted in Partial fulfillment of the requirements for the degree of doctor of philosophy in The Faculty of Graduate Studies, School of Community and Regional Planning, University of British Columbia, Canada.

[29] Wackernagel, M., Onisto, L., Bello P., Callejas, A., López I., Méndez J., Suárez A. y Suárez M. (1999), National natural capital accounting with the ecological footprint concept, Ecological Economics 29, pp. 375-390.

[30] Wackernagel, M., Chambers, N. y Simmons C. (2000), Sharing Natures Interest. Ecological Footprints as an indicator of sustainability. Earthscan publications Ltd, London and Sterling, VA.

[31] WCED (1987). Report of the World Commission on Environment and Development: Our Common Future, disponible en: http://www.undocuments.net/our-common-future.pdf

[32] Wiedmann, T., Minx, J., Barrett, J., y Wackernagel, M. (2006). Allocating ecological footprints to final consumption categories with input-output analysis. Ecological Economics, 56(1), 28-48. doi:10.1016/j.ecolecon.2005.05.012

[33] Wiedmann, T. (2009). A review of recent multi-region input-output models used for consumption-based emission and resource accounting. Ecological Economics, 69(2), 211- 222. doi:10.1016/j.ecolecon.2009.08.026 
Anexo 1

\begin{tabular}{l|crrrr}
\multicolumn{7}{c}{ Tabla 2 } \\
\multicolumn{7}{c}{ Media y desviación estándar } \\
\multicolumn{1}{c}{ Variable } & Obs & Mean & Std. Dev. & \multicolumn{1}{c}{ Min } & \multicolumn{1}{c}{ Max } \\
\hline energy & 32 & 6,442 & 4,742 & 1,258 & 17,758 \\
pib & 32 & 488,832 & 504,154 & 87,658 & $2,673,066$ \\
rsu & 32 & 1,357 & 1,418 & 239 & 6,958 \\
hotel & 32 & 21,009 & 17,391 & 3,952 & 86,588 \\
vh & 32 & $1,148,276$ & $1,127,564$ & 240,445 & $4,787,187$ \\
eto & 32 & 132,211 & 115,304 & 28,114 & 534,838 \\
viviendas & 32 & 893,987 & 751,560 & 178,079 & $3,749,106$
\end{tabular}

Pib: Producto Interno Bruto en millones de pesos a precios corrientes (Sistema de Cuentas Nacionales, INEGI); rsu: residuos sólidos urbanos en miles de toneladas anuales (SEDESOL); vh: vehículos de motor registrados en circulación (Estadísticas de vehículos de motor registrados en circulación, INEGI); energy: consumo de energía eléctrica en gigawatts por hora (Comisión Federal de Electricidad); hotel: cuartos de hospedaje (Secretaría de Turismo e INEGI); eto: establecimientos (Censo Económico, INEGI); viviendas: viviendas particulares habitadas (Censo de Población y Vivienda, INEGI).

Tabla 3

Matriz de correlación entre variables

\begin{tabular}{l|ccccccr} 
& energy & pib & rsu & hotel & vh & eto & viviendas \\
\hline energy & 1.0000 & & & & & & \\
pib & 0.7453 & 1.0000 & & & & & \\
rsu & 0.8036 & 0.8213 & 1.0000 & & & & \\
hotel & 0.3008 & 0.3632 & 0.3465 & 1.0000 & & & \\
vh & 0.8239 & 0.8821 & 0.9590 & 0.3957 & 1.0000 & & \\
eto & 0.7142 & 0.7551 & 0.9582 & 0.3702 & 0.9201 & 1.0000 & \\
viviendas & 0.7943 & 0.7550 & 0.9765 & 0.3543 & 0.9204 & 0.9715 & 1.0000
\end{tabular}

\section{Tabla 4}

Componentes principales/correlaciones

\begin{tabular}{|c|c|c|}
\hline \multicolumn{2}{|l|}{ Númer } & 32 \\
\hline \multicolumn{2}{|c|}{ Número de componentes } & 7 \\
\hline Traza & & 7 \\
\hline Rho & & 1 \\
\hline Diferencia & Proporción & Acumulada \\
\hline 4.6159 & 0.7786 & 0.7786 \\
\hline 0.4676 & 0.1192 & 0.8978 \\
\hline 0.1026 & 0.0524 & 0.9502 \\
\hline 0.2178 & 0.0377 & 0.9879 \\
\hline 0.0183 & 0.0066 & 0.9946 \\
\hline 0.0183 & 0.0040 & 0.9986 \\
\hline- & 0.0014 & 1.0000 \\
\hline
\end{tabular}




\section{Tabla 5}

\section{Componentes principales (eigenvectores)}

\begin{tabular}{lllllllll}
\hline Variable & Comp1 & Comp2 & Comp3 & Comp4 & Comp5 & Comp6 & Comp7 & Unexplained \\
\hline enery & 0.3680 & -0.1175 & 0.5863 & 0.6829 & 0.0741 & 0.1493 & 0.1131 & 0.0000 \\
pib & 0.3765 & -0.0186 & 0.5149 & -0.6855 & 0.3491 & 0.0177 & -0.0264 & 0.0000 \\
rsu & 0.4190 & -0.1148 & -0.2087 & -0.0046 & -0.0828 & -0.6670 & 0.5620 & 0.0000 \\
hotel & 0.1921 & 0.9775 & -0.0113 & 0.0769 & 0.0154 & -0.0322 & 0.0170 & 0.0000 \\
vh & 0.4193 & -0.0481 & 0.0375 & -0.1502 & -0.8336 & 0.1104 & -0.3015 & 0.0000 \\
eto & 0.4058 & -0.0677 & -0.4751 & -0.0447 & 0.1625 & 0.6801 & 0.3379 & 0.0000 \\
viviendas & 0.4121 & -0.1013 & 0.3469 & 0.1822 & 0.3799 & -0.2382 & -0.6821 & 0.0000 \\
\hline
\end{tabular}

Tabla 6

Kaiser-Meyer-Olkin measure of sampling adecuacy

\begin{tabular}{ll}
\hline Variable & kmo \\
\hline pib & 0.7932 \\
rsu & 0.9207 \\
hotel & 0.8358 \\
energy & 0.8914 \\
eto & 0.8167 \\
vh & 0.8009 \\
viviendas & 0.7451 \\
Overall & 0.8157 \\
\hline
\end{tabular}


Tabla 7

Factores de rendimiento y equivalencia por tipo de uso de suelo

\begin{tabular}{|c|c|c|c|c|c|c|}
\hline Entidad & fr agrícola & fe agrícola & fr pastos & fe pastos & fr forestal & fe forestal \\
\hline Aguascalientes & 0.5 & 2.3 & 31.5 & 0.1 & 0.0 & 2.1 \\
\hline Baja California & 1.4 & 1.3 & 9.0 & 0.1 & 0.0 & 11.2 \\
\hline Baja California Sur & 1.4 & 1.3 & 17.2 & 0.0 & 0.0 & 10.6 \\
\hline Campeche & 0.6 & 1.7 & 8.4 & 0.0 & 0.0 & 4.6 \\
\hline Chiapas & 0.5 & 2.1 & 2.7 & 0.3 & 0.0 & 3.6 \\
\hline Chihuahua & 1.5 & 1.4 & 6.0 & 0.1 & 0.0 & 8.1 \\
\hline Coahuila & 0.4 & 1.2 & 6.7 & 0.1 & 0.0 & 14.5 \\
\hline Colima & 0.8 & 2.2 & 4.1 & 0.2 & 0.0 & 3.5 \\
\hline Ciudad de México & 0.3 & 2.3 & 9.7 & 0.1 & 0.0 & 2.6 \\
\hline Durango & 0.5 & 1.6 & 2.0 & 0.4 & 0.0 & 6.3 \\
\hline Estado de México & 0.9 & 2.4 & 0.0 & 0.0 & 0.1 & 1.6 \\
\hline Guanajuato & 0.9 & 1.9 & 13.6 & 0.0 & 0.1 & 0.7 \\
\hline \begin{tabular}{|l|} 
Guerrero \\
\end{tabular} & 0.6 & 1.9 & 1.3 & 0.3 & 0.0 & 4.7 \\
\hline Hidalgo & 0.6 & 2.1 & 8.1 & 0.1 & 0.0 & 1.2 \\
\hline Jalisco & 1.3 & 2.1 & 13.7 & 0.1 & 0.0 & 3.6 \\
\hline Michoacán & 0.9 & 2.0 & 4.7 & 0.1 & 0.0 & 2.9 \\
\hline Morelos & 0.7 & 2.2 & 5.6 & 0.1 & 0.0 & 1.4 \\
\hline Nayarit & 1.0 & 1.8 & 4.4 & 0.1 & 0.0 & 4.1 \\
\hline Nuevo León & 0.5 & 1.8 & 1.4 & 0.2 & 0.0 & 5.2 \\
\hline Oaxaca & 0.3 & 1.9 & 1.4 & 0.2 & 0.0 & 4.8 \\
\hline Puebla & 0.4 & 2.3 & 3.4 & 0.2 & 0.1 & 2.8 \\
\hline Querétaro & 0.7 & 2.2 & 16.4 & 0.1 & 0.0 & 2.0 \\
\hline Quintana Roo & 0.2 & 1.3 & 0.6 & 0.1 & 0.0 & 10.5 \\
\hline San Luis Potosí & 0.2 & 1.9 & 8.8 & 0.1 & 0.0 & 3.7 \\
\hline \begin{tabular}{|l|} 
Sinaloa \\
\end{tabular} & 2.0 & 2.1 & 48.4 & 0.0 & 0.0 & 2.4 \\
\hline \begin{tabular}{|l|} 
Sonora \\
\end{tabular} & 1.6 & 2.4 & 1.9 & 0.3 & 0.3 & 2.0 \\
\hline Tabasco & 0.4 & 1.8 & 4.3 & 0.1 & 0.0 & 0.7 \\
\hline Tamaulipas & 0.8 & 2.2 & 1.4 & 0.1 & 0.1 & 2.1 \\
\hline Tlaxcala & 0.7 & 1.5 & 23.4 & 0.0 & 0.1 & 0.3 \\
\hline Veracruz & 0.5 & 2.8 & 3.0 & 0.5 & 0.0 & 1.9 \\
\hline Yucatán & 0.2 & 1.8 & 14.3 & 0.0 & 0.0 & 4.7 \\
\hline Zacatecas & 0.1 & 1.9 & 11.0 & 0.0 & 0.0 & 3.3 \\
\hline
\end{tabular}

Fuente: Estimaciones con base en INEGI, SAGARPA, FAOSTAT 
Tabla 8

Tipos de uso de suelo en hectáreas

\begin{tabular}{|l|r|r|r|r|r|}
\hline \multicolumn{1}{|c|}{ Entidad } & \multicolumn{1}{c|}{ Agrícola } & Pastizales & Área Forestal & Zonas urbanas & Superficie continental \\
\hline Aguascalientes & 179,726 & 41,925 & 291,793 & 22,379 & 555,867 \\
\hline Baja California & 410,499 & 322,370 & $6,287,339$ & 90,871 & $7,350,701$ \\
\hline Baja California Sur & 166,202 & 15,173 & $2,469,323$ & 26,266 & $7,396,898$ \\
\hline Campeche & 904,044 & 85,238 & $4,448,975$ & 25,672 & $5,727,716$ \\
\hline Chiapas & $1,376,865$ & $1,545,654$ & $4,199,189$ & 60,202 & $7,361,186$ \\
\hline Chihuahua & $2,046,405$ & 679,454 & $21,622,373$ & 147,761 & $24,697,335$ \\
\hline Coahuila & 629,323 & 638,325 & $13,365,623$ & 143,115 & $15,067,115$ \\
\hline Colima & 110,160 & 87,401 & 316,504 & 11,675 & 559,827 \\
\hline Ciudad de México & 23,641 & 4,622 & 47,422 & 70,710 & 148,646 \\
\hline Durango & 907,970 & $1,790,443$ & $6,249,454$ & 22,548 & $12,213,120$ \\
\hline Estado de México & 901,175 & & $1,065,367$ & 208,282 & $2,226,737$ \\
\hline Guanajuato & $1,562,353$ & 222,717 & $1,124,806$ & 95,102 & $3,033,978$ \\
\hline Guerrero & 935,753 & $1,132,553$ & $4,153,795$ & 76,231 & $6,356,487$ \\
\hline Hidalgo & 869,372 & 228,408 & 876,957 & 80,880 & $2,065,455$ \\
\hline Jalisco & $1,585,301$ & 744,851 & $4,850,338$ & 168,888 & $7,796,438$ \\
\hline Michoacán & $1,355,224$ & 626,976 & $3,414,289$ & 8,609 & $5,829,629$ \\
\hline Morelos & 182,009 & 47,416 & 206,100 & 22,113 & 485,941 \\
\hline Nayarit & 492,469 & 154,803 & $1,985,128$ & 23,579 & $2,781,801$ \\
\hline Nuevo León & 834,781 & 975,161 & $4,205,458$ & 101,032 & $6,335,853$ \\
\hline Oaxaca & $1,381,067$ & $1,372,250$ & $6,295,474$ & 149,631 & $9,395,978$ \\
\hline Puebla & 753,241 & 618,260 & $1,674,763$ & 49,908 & $3,422,824$ \\
\hline Querétaro & 391,153 & 97,672 & 630,022 & 36,193 & $1,158,927$ \\
\hline Quintana Roo & 262,399 & 183,720 & $3,773,023$ & 40,783 & $4,455,627$ \\
\hline San Luis Potosí & $1,214,197$ & 289,220 & $4,314,632$ & 56,007 & $6,049,994$ \\
\hline Sinaloa & $1,639,334$ & 58,637 & $3,417,027$ & 67,776 & $5,680,290$ \\
\hline Sonora & $1,030,641$ & $1,281,440$ & $1,501,859$ & 75,781 & $18,084,046$ \\
\hline Tabasco & $1,058,083$ & 506,496 & 711,674 & 21,004 & $2,469,460$ \\
\hline Tamaulipas & $2,225,457$ & $1,170,502$ & $3,795,182$ & 81,075 & $7,942,606$ \\
\hline Tlaxcala & 267,441 & 25,271 & 84,075 & 15,619 & 397,397 \\
\hline Veracruz & $1,639,843$ & $2,874,908$ & $2,091,132$ & 288,194 & $7,146,131$ \\
\hline Yucatán & 640,894 & 66,069 & $3,094,633$ & 72,593 & $3,918,934$ \\
\hline Zacatecas & $1,722,763$ & 157,314 & $5,347,484$ & 41,988 & $7,447,971$ \\
\hline & & & & & \\
\hline
\end{tabular}

Fuente: CONAFOR-SEMARNAT (2015), INAFED 